Similarly, this case underlines the importance of human monitoring of and, where necessary, intervention in the ways in which the internal search functions of retailers' websites deal with words that are also third-party trademarks. In its ruling on 2 May, the High Court refused Amazon permission to appeal the main ruling with respect to the operation of the search function and displays on the Amazon website. If Amazon wishes to take the case further, it will have to apply to the Court of Appeal for permission to appeal.

Jonathan Mayner, solicitor, Osborne Clarke, London

\title{
Nuisance calls latest
}

\section{Thomas Spanyol}

Journal of Direct, Data and Digital Marketing Practice (2014) 15, 348-350. doi:10.1057/dddmp.2014.31

\section{Who: OFCOM}

Where: UK

When: 27 February 2014

Law stated as at: 6 March 2014

\section{What happened}

\section{Silent and abandoned calls}

Telecommunications regulator OFCOM published its quarterly update on consumer complaints on 27 February. This time last year, OFCOM's report revealed a dramatic spike in complaints, in particular with reference to silent and abandoned calls and the lack of use by marketers of the UK's 'do not call' list maintained by the Telephone Preference Service (TPS).

It seems clear that the area of silent calls continues to be an issue. These are mostly the result of telemarketers using 'predictive dialler' technology, which automatically dials numbers and then matches up a call centre agent with the recipient when the phone is picked up. The aim is to maximize the amount of time call centre agents spend speaking to consumers. However, problems arise if there is no call centre agent available to take the call. This results in the consumer hearing silence, which can cause recipients distress and lead to complaints to OFCOM, which under Section 130 of the Communications Act 2003 has the power to impose fines of up to $£ 2$ million.

OFCOM's report from this time last year showed that between December 2012 and January 2013 complaints jumped from 1,788 to 2,398. This year's report shows in a graph on page six that, following a peak of 3,900 complaints in April 2013, the overall trend for complaints in this area has been one of bumpy decrease. By December 2013, this figure had more than halved, with only 1,704 complaints recorded. However, January saw this figure rise again to 2,507, higher than in January 2013. 


\section{Joint ICO and OFCOM action}

\section{Tackling number spoofing}

\section{Prohibited unsolicited marketing calls}

\section{ICO seeking stronger powers}

OFCOM and the UK Information Commission's Office (ICO) published an update to their joint action plan for tackling nuisance calls and messages on 3 March 2014. In this update, OFCOM highlights that abandoned and silent calls are being made by a large number of organisations, each generating a relatively small number of complaints. This makes enforcement a challenge, as does tracing the source of such calls, given that organisations making the calls often choose to withhold their number or present an invalid phone number.

OFCOM continues to look into how it can address silent calls and is currently investigating Redress Financial Management Ltd, trading as Redress Claims, for an alleged excessive number of abandoned calls between 15 August and 15 November 2012. It has also taken informal enforcement action against 25 organisations following consumer complaints, which has led to complaints ceasing against 16 of the 25 numbers in question and reducing 'significantly' for six. The remaining three cases are the subject of 'ongoing' work.

On the technical side, the regulator is working with the ICO and industry to improve its call-tracing capabilities. OFCOM also met with the US Federal Trade Commission (FTC) in November 2013, in order to discuss approaches to cracking down on number spoofing.

Going forward, the regulator will be teaming up with the FTC, the Canadian Radio-television and Telecommunications Commission and the Australian Communications \& Media Authority to 'explore technical, regulatory and law enforcement approaches to caller ID spoofing'.

Conversely, marketers' use of the UK's 'do not call' list appears to have improved. Last year, we reported a significant increase in complaints in this area between December 2012 and January 2013, with complaints nearly doubling from 4,962 to 9,498 . The TPS felt that this may have reflected increased marketing activity by companies offering help with payment protection insurance mis-selling claims. Calling consumers who have registered with the 'do not call' list is a breach of the Privacy and Electronic Communications Regulations 2003 (PECR).

While improvement in this area has been somewhat bumpy, complaints have certainly fallen - from a peak of 10,373 complaints in February 2013 to 4,826 as of January 2014. Some of this may be the usual Christmas and New Year dip, but year-on-year it does appear that the large increase in complaints appears to have been reversed.

OFCOM and the ICO will continue to work together in this area, and have been working with government on proposed changes to the regime governing nuisance calls, for example the recent report of the Culture, Media and Sport Committee and the All Party Parliamentary Group on Nuisance Calls' report on unsolicited marketing. Also, in July 2013 the ICO presented a business case to the Department for Culture, Media and Sport setting out reasons why remedies under PECR should be improved. At present, civil monetary penalties can only be obtained if it can show 'substantial damage or distress' - the ICO would like to see this threshold lowered to something like 'irritation and nuisance' to act as a better 


\section{Why this matters}

deterrent to advertisers, a move supported by Which? and, it appears from recent pronouncements, by Minister of State for Justice and Civil Liberties Simon Hughes MP.

The spiralling numbers of complaints of this time last year seem to have reduced, but it is clear that work remains necessary, particularly on silent and abandoned calls and prohibited unsolicited marketing. The key will be whether a reduced threshold for monetary penalty notices of up to $£ 500,000$ is introduced. But it remains to be seen whether this becomes a reality and whether legislative draftspersons can come up with workable language for an 'irritation and nuisance' based test.

Thomas Spanyol, associate, Osborne Clarke, London

\section{Midata initiative update}

\section{Emma Harrington}

Journal of Direct, Data and Digital Marketing Practice (2014) 15, 350-351. doi:10.1057/dddmp.2014.32

Who: The Coalition Government

Where: UK

When: 11 March 2014

Law as stated at: 11 March 2014

\section{What happened}

The Government's midata action plan began in April 2011 with the publication of the report 'Consumer empowerment strategy: Better choices, better deals'. The idea was that consumers would be able to access their transaction and consumption data easily from service suppliers in order to empower them to make the best choice for their needs, primarily in the four core sectors of energy, mobile telecoms, current accounts and credit cards.

After the introduction of the midata concept, BIS launched a consultation in July 2012 to which the Government published a response in November 2012. The Government proposed to take forward a voluntary programme for businesses in respect of midata, but also to introduce legislation to give the Government power to impose midata. This was followed through in April 2013 with the passing of the Enterprise and Regulatory Reform Act (Sections 89-91). This gave the Secretary of State the ability to issue secondary legislation imposing a duty on suppliers to provide midata to their customers in the four key sectors referred to above (with the ability to extend this to any supplier of goods and services). 